\title{
Basic Architecture for ICT Integration in the Canary Educational System
}

\author{
Pedro Baquero, Alfredo Santana, Ignacio Zubiria and Manuel Prieto \\ Consejería de Educación, Cultura y Deportes. Gobierno de Canarias
}

\begin{abstract}
This article describes a global solution that covers the ICT infrastructure necessities of the educational community. The focus has started from the principle that the school has autonomy in the development of its educational project. And, at the same time, there are networks of people and schools that belong to a corporation system. The global solution consists of a basic technological architecture composed of three evolutionary projects (the Individualized Networks of the Schools, the Integrated Broadband Network and the Management System). The strategic bases for the design have been that the basic necessities of the educational community and the deployment of ICT infrastructure should be synchronized with the objectives for transforming the educational system. This study has been framed inside MEDUSA project. This project is an initiative of the Government of the Canary Islands (Spain) to extend the ICT use in the educational system.
\end{abstract}

Key words: ICT infrastructure, schools, educational system, corporate networks.

\section{INTRODUCTION}

In the last years a quick incorporation of ICT (Information and Communication Technologies) to the educational system has taken place. In this article the design of a global basic architecture for integrating ICT in the non university educational system is described. The strategic bases for the design have been that the basic necessities of the educational community and the deployment of ICT infrastructure should be synchronized with the objectives for transforming the educational system. Thereby, in the global 
design, different parts of ICT infrastructure have been integrated together with processes that eliminate obstacles for ICT integration in education. As reported in Pelgrum (2001) obstacles are not only infrastructural. In his study 38 obstacles were reported. The top 10 obstacles consisted of a mixture of material and non material conditions. The material conditions were insufficient numbers of computer equipment and of Internet accesses. As non-material conditions were a lack of skill of teachers and lack of supervisory and technical staff. While the material conditions are fulfilled with the deployment of ICT infrastructure, the non-material conditions require the 'deployment' of human resources, services and management processes. Therefore, infrastructure, services, human resources and management processes have been included in the technological architecture. The result has been a basic technological architecture composed of three evolutionary projects: the Individualized Networks of the Schools, the Integrated Broadband Network and the Management System. From a common strategy, each one of these projects has its own evolutionary strategy. This basic technological architecture has been designed considering that at the same time we are planning, designing, building, using and operating. This study has been framed inside the MEDUSA project. This project is an initiative of the Government of the Canary Islands to extend ICT use in the educational system.

Section 2 summarizes where the MEDUSA project is framed and what its objectives are. Section 3 describes bases for the strategic design of the basic technological architecture. Section 4,5 and 6 describe respectively the Individualized Networks of Schools, the Integrated Broadband Network and the Management System. Finally in section 5 is the conclusion of this work.

\section{THE MEDUSA PROJECT}

Canary Islands is a region of Spain formed by seven islands. It is located in the Atlantic Ocean, $1,250 \mathrm{~km}$ from Europe and $210 \mathrm{~km}$ from the African coast. It has a population of $1,694,477$ inhabitants, $40 \%$ of them concentrated in the metropolitan zones of the two main islands. The territory is strongly fragmented due to its insularity and geography (ISTAC, 2003). The non-university educational system (Cabrera \& Afonso, 2002; ISTAC, 2003; CECD, 2003) is formed by 850 administrative workers, 301,622 pupils, 19,660 teachers and 1,264 schools. At the beginning of year 2001 the penetration was 23.6 students per computer with a significant number of obsolete computers. On the other hand, available computer material in schools was used to cover derived necessities of ICT conception as a 
curricular subject, ICT not being approached as a didactic instrument in different areas and curricular subjects. Schools did not have a data infrastructure that facilitated installation of ICT equipment. In year 2000 the number of schools with Internet access was about $24 \%$, and only $2.2 \%$ had a WEB site. On the other hand, while there were some teachers with positive ICT attitudes, there were other teachers who had resistances of different intensity toward ICT use.

The Canary Islands educational system is framed inside the Spanish educational system (Cabrera \& Afonso, 2002; CIDE, 2002) characterized by a decentralized model of administration that distributes the responsibilities mainly among National Government, Regional Governments and the educational centres. National Government has exclusively reserved the exercise of responsibilities that safeguard the homogeneity and substantial unity of the educational system. Regional Government deals with, among other duties, the administrative ownership in their territory, administration of personal, orientation and attention to the pupil, helps and grants, etc. Regulations have been establishing the principle of autonomy of schools. They have capacity for decision-making in curricular aspects. Educational centres or schools should elaborate three different documents where their pedagogic and curricular organization is reflected: the educational project, the curricular project and the didactic programming. It is therefore at the school where the initiative is focused on including ICT for support for the educational project. Regional Governments will be able to motivate and to support this type of initiative.

At the present time the Government of the Canary Islands, through the Department of Education, Culture and Sports, is developing the MEDUSA project (CECD, 2003), which is a specific ICT project for non-university education. It is basically conceived as an integral programme where all the educational elements are identified. This project is bounded to the educational administration and the public schools of Canary Islands. As shown in table 1 , it is a project with very wide objectives. This project is framed inside CANARIAS DIGITAL programme (GC, 2003) in accordance with the strategic policy for facilitating the incorporation of the Canary Islands to the Information Society. The MEDUSA project is being developed in two Phases: Phase I (2001-2004) and Phase II (2004-2006). At the end of Phase II all schools will have Internet connection and a WEB site and there will be a ratio of less than 12 pupils per computer. It is mainly funded by the European Commission, through FEDER (Fonds Européen de Développement Régional) and FSE (Fonds Social Européen) programmes. At the present time THE MEDUSA project is at the beginning of Phase II and it is at a level which allows its evaluation. 


\section{OBJECTIVES OF THE PROJECT}

The ultimate and general aim of 'Proyecto MEDUSA' is to integrate ICT in educational non-university environments in the Canaries in an effective way. This integration should lead us to qualified teachers and students in a short/middle-term period of time, so that they are used to logical and critical use of tools and technological resources, and that will permit new ways of teaching and learning, and that will also help to establish new ways of communication and contribution with other educational agents.

\begin{tabular}{|c|}
\hline MEDUSA OBJETIVES \\
\hline $\begin{array}{l}\text { To create a mark of cooddinated performance and of collaboration among the } \\
\text { different departments in matters related with the ICT }\end{array}$ \\
\hline $\begin{array}{l}\text { To adapt the school environments for the integration of the ICT like didactic } \\
\text { resource, as curricular content, as communication vehicle and like instrument of } \\
\text { academic and administrative administration }\end{array}$ \\
\hline $\begin{array}{l}\text { To endow with solid infrastructures to the centers of that facilitate the access from } \\
\text { the educational agents to the Society of the Information }\end{array}$ \\
\hline $\begin{array}{l}\text { To promote the use of the } \mathrm{CT} \text { in the schools using creative, interactive and flexible } \\
\text { learning environments in the different teaching levels in the areas and curricular } \\
\text { matters }\end{array}$ \\
\hline $\begin{array}{l}\text { To educate to teachers for using rationally and logically } I C T \text {, qualifying them to } \\
\text { elaborate and to adapt educational applications }\end{array}$ \\
\hline $\begin{array}{l}\text { To approach of resolvedly form and practically the development and organization of } \\
\text { contents using new tools and communication supports }\end{array}$ \\
\hline $\begin{array}{l}\text { To promote the use of the ICT in the areas of academic and administrative } \\
\text { administration of the centers }\end{array}$ \\
\hline $\begin{array}{l}\text { To promote innovation projects and educational investigation using the ICT to } \\
\text { define pedagogic models of integration of these technologies and also organization } \\
\text { models in the centers }\end{array}$ \\
\hline $\begin{array}{l}\text { To faclitate the access to educational telematy networks, databases, electronic } \\
\text { mail etc, developing in students and teachers the capacity to access, to recover to } \\
\text { organize, to try and to transmit the information for educational use }\end{array}$ \\
\hline To explore and to consolidate the ICT for the pupil with special educational needs \\
\hline
\end{tabular}

\section{Table 1. MEDUSA Objectives}

The immediate pursued benefits are, among others, to generalize access to information and contents in the Internet, to create flexible and more interesting ways of teacher training, to improve the administrative and academic management of schools, to facilitate the publication and exchange 
of experiences, and the creation of virtual communities for the different educational agents, apart from creating communication infrastructures to bear the Project. In the middle-term the effects should correspond with the capacity of citizens to continually learn, and to adapt themselves to the new work situations and relationships born from the evolution of the technology.

\subsection{Strategic Focal Points of the Project}

A project of this dimension requires a set of actions that become the basic pillars for a correct execution of it, and these actions are carried out in a coordinated and complementary way. That is why Departments and/or General Management take part and collaborate in any of the areas of action of the Project (communications, infrastructure, equipment, teacher training, schools management, and so on). This contribution is coordinated by the management and executive team of the Project.

The first action initiated in the project is the creation of infrastructures and equipment in the Management Department of the Project, in the Central Services of the Department of Education, in the 'Teachers Centres' and in schools. This is the most difficult process, and it permits us to arrange and enable all those logical and physical elements that will provide the technological basis for the Project to revolve.

The second basic pillar consists of training teachers, students and other agents involved in the execution of the Project. Users training is conceived as functional, practical and adapted to the contexts, to the materials and environment in which the Project develops.

Training contents and offers are flexible. They are collected in an annual Training Plan, provided with a modular structure to facilitate teachers in making up their training itinerary. This Plan is continually updated and improved. The course contents are organized in several 'training lines' which are slightly differentiated. Thus a first line is defined as 'instrumental training'. Its objective is to qualify teachers and other educational agents so that they are able to use equipment and generic applications up to an acceptable level of safety. A second line, also instrumental, intends to provide certain users with more intense training upon equipment and specific basic applications related to services and better use of Network resources.

A second training guidance is that of 'Use and exploitation of Administrative and Academic Management Applications', to take advantage of the functionalities of these applications, so that users are able to modernize and improve schools management and school libraries.

The third line of formation is oriented to 'ICT integration in the syllabus'. It intends to promote an open attitude, among teachers, toward the 
S.I. and let them know general or specific applications so that they can use them in their teaching activities. A second more advanced training level will enable teachers to feel at ease in certain environments and produce their own applications.

'Technologies as a curricular subject' is another orientation in teacher training. It has to do with the need to undertake contents related to Technology in Secondary Education, data processing and other specific subjects included in specialized teaching.

Keeping in mind the basis on which the Project develops, training through the Internet is prompted. This kind of training is tremendously important and useful in a geographically dispersed area such as the Canaries. The use of training through the Internet will be shared with presential training, and a mixture of both. In general, any training activity will be backed up with tools ready to be used in the Internet, and that will provide users with different services.

The provision of contents is another strategic focal point of the Project. The shortage of educational and specific contents related to ITC, or borne by them, has not favoured the approach to ICT in schools, as well as integration and use of ICT as instrumental support in the different subjects. The policy of content provision is undertaken in different ways. On one hand, a percentage of ICT content will be released via publishers; another set of content will be self-developed, adapting them to context or participating in similar national or European projects. On the other hand, available content located in the Internet, which is conveniently catalogued and classified, can be also used.

In this sense, the promotion and support of innovation and educational research projects will be another source of provision, with the added value that these materials are already contextualized in specific classroom situations, so that the level of motivation is very high, because they will be suggested by teachers that work with them.

'Proyecto MEDUSA' is carried out and fulfilled when launching educational activities in the classrooms, involving students in those activities. Students are the main recipients of the Project; and it is in the environments created in schools, in the classrooms and in the network, where the Project acquires its true dimension. The progressive transfer of the use of the technological elements to the classrooms is considered fundamental. The ultimate aim is the natural media integration in the classrooms for teaching purposes.

In order to encourage and support the deployment of the Project on a personal level, there is a team of advisers (teachers specialized in the use of technologies in the classroom and educational levels) who advice with the support and collaboration of the 'teachers centres'. 


\section{TECHNOLOGICAL BASES FOR THE STRATEGIC DESIGN}

Our vision has started from the school autonomy in the development of its educational project. Efforts should concentrate on the teaching-learning process using ICT. And, at the same time, there are people and school networks that belong to a corporate system. The ideal technological solution should give answers to two environments: the school and the corporate environment. The methodology has started locating the characteristics that should complete the necessities of these environments. At the same time the solution should go beyond endowing schools with an ICT global infrastructure and that should be framed inside all the objectives of the MEDUSA project eliminating obstacles for ICT integration (Pelgrum, 2001). Thus, to execute this technological solution, a series of characteristics has also been identified and they should complete the development of the project. The educational system has a series of particularities that make it a unique environment with its own characteristics and differences with respect to other organizations:

- There exist a larger number of schools with, in general, not very reliable communications lines.

- There exists great diversity of software. They are mainly educational applications instead of the productivity software (e.g., office applications) used in most of other organizations.

- The ICT applications are continually being installed and uninstalled. If there does not exist an adequate management, the computer environments become unstable.

- The educational community has important levels of autonomy. Their initiative and favourable attitudes can lead to an intensive ICT use.

Therefore solutions based on decentralized environments have been considered. Solutions based on centralized systems like ASP (Application Service Providers) have been discarded mainly because they need robust communications and standard applications (Harney, 2002).

At the beginning of the year 2001 we saw that there were low levels of ICT infrastructure in the Canary Islands educational system. There has been a considerable effort to endow all schools with equipment and infrastructure. As seen above, schools are framed inside a system that provides them autonomy with respect to the development of their educational project, the ICT educational project would be included inside. On the other hand, it is at the school where the direct contact with the pupil takes place and, therefore, where the teacher can apply and use ICT inside his particular strategy of working and teaching. 
Schools and the administrative departments are all members of the educational system. The corporate network should facilitate the creation of knowledge networks. This network should favour the exchange of data and experiences and the improvement of corporate administrative processes. Also, it should expand access to the Internet for all schools. This network should be opened to incorporation of new services.

The technological solution should be fully integrated with the objectives of the MEDUSA project. The rhythm of development will depend, apart from the available budget, on the technology and also on other factors such as the market, the investment capacity of the operators and the services demanded by the citizen and public administration.

An objective for the future is to create a basic technological architecture for the educational system of the Canary Islands. It should be the infrastructure that gives a global solution of connectivity and support to all ICT applications and services. This basic technological architecture should have the following parts:

- A technological solution inside the school that is sufficiently uniform and at the same time completes the educational autonomy of the school, the mobility inside the school, the flexibility and robustness characteristics. Given the great number of schools, it will be carried out by gradual deployment. Each of these schools will be integrated in the educational system through a corporate network.

- The corporate technological solution should assure the integration of services and universality to the whole educational community. It will give a response to the necessities of broadband. Also, it will allow the mobility of users outside their schools.

- A technological and organizational solution that should be friendly with all type of users, especially the basic user, should be designed to support intelligence approaches in administration and operation and should support characteristics of the development of a project.

Following this model as reference, the final technological architecture will contemplate each one of the identified parts. This architecture will evolve toward a global solution that will be materialized with the development of three clearly differentiated projects:

- The Individualized Networks of the Schools.

- The Integrated Broadband Network.

- The Management System.

With these three projects all the characteristics would be aimed towards necessities of the school environments and the corporate environment. The previous technical projects become evolutionary projects when they converge on a global solution that is continuously evolving. 
These three evolutionary projects should be consistent with the technological trends and thereby fulfill the long term characteristic. As clear trends we have the evolution of services toward IP technology (Goncalves \& Niles, 1998), increase of broadband in access and incorporation of wireless accesses (Zamir, 2000). In the election of the technological solution these three trends has been considered.

\section{INDIVIDUALIZED NETWORKS OF SCHOOLS}

The deployment of ICT equipment and infrastructure for all schools has been defined. Each school should be endowed with ICT infrastructure to carry out its ICT educational project. There exist diverse types of schools in the Canary educational system, although the most important are primary and secondary schools. In a general way each school has an administrative staff, seminars or teachers' rooms, an assembly hall, a library, classrooms and computer classroom. A standard technological solution has been designed to adapt each school to its ICT educational project. This standard solution consists in:

- A local-area server. Its administration, including backup copies, is carried out remotely and centralized from ICT Centre (as described in section 6.2). The local-area server has the necessary services for educational autonomy of the school. Teachers and administrative personnel have their own accounts and their own directory where they can house all their information.

- A MEDUSA classroom with access to the educational network composed by about fifteen computers. The MEDUSA classroom has a standard configuration. The objective of this classroom is the support for teaching to all subjects. In general, these subjects do not have ICT curricular contents. It is intended that the MEDUSA classroom should be a very stable and robust environment, in this way a very strict permission policy exists for the installation of applications. On the other hand, each school used to have a computer classroom for specific computer teaching. In some cases these computer classrooms have also been endowed with equipment. Each school establishes its administration policy for computer classrooms, so computer teachers can be as free as possible. These classrooms are integrated inside the ICT infrastructure of the school and are isolated through a router to avoid conflicts with the rest of the network.

- Access to the corporate network is given for administrative services, library and seminars. In general, the corporate applications work in a 
WEB architecture. Each seminar is endowed with a minimum of a computer with access to the corporate resources of the the Government of the Canary Islands. Also, the library is endowed with a computer and with the access to the corporate application of bibliographical resources.

- Access to the educational network is given to all the 'classroom corners'. In general, the 'classroom corner' is located next to the teacher's table and blackboard. Each classroom is endowed with one or two double network points placed in the 'classroom corner'.

- Endowment with computers and peripherals. Schools are endowed with computer equipment for general use. This equipment is usually made up of a limited number of computers, peripherals (printers, scanner, etc), a notebook computer and a projector.

- The MEDUSA classroom and computer classrooms are wired to give service to all computers. Each classroom is endowed with two or four network points placed in the 'classroom corners'. Each room (library, seminars, assembly hall, administration and address) is endowed with a minimum of two network points. The whole school is endowed with structured cabling together with electrical infrastructure. Structured cabling category 5/clase $\mathrm{E}$ has been used. The local-area network is Fast Ethernet (100 Mbps) implanted with switches. It is tried to endow with at least a double point of network to all the dependences. This way guarantees that the school has a high flexible infrastructure that allows mobility among the different classrooms and rooms can evolve toward bigger speeds than 100 Mbps (Saunders, 1996) and is easily manageable through changing remotely configurations of switches.

Therefore, a uniform solution has been created in all the schools. The experience has allowed checking that this solution is adjusted to all ICT educational projects of the schools. The aspects that vary from one school to another are the number of computers and peripherals. The characteristics of the computers also varies due to market improvements that take place during the lifetime of deployment. A complete inventory control is acquired remotely through using intelligent agents in each computer. It facilitates the administration of the equipment. Permission policies have been created to have robust environments. Thus, the teachers can not directly administer and install applications in computers, in servers and in MEDUSA classrooms. Anyway, each school can install its own educational applications for which a management model has been created that permits more autonomy to the school. Different user profiles have been defined: the basic, the advanced and the administrator user. All the pupils and most of the teachers are basic users. Only the advanced and administration users can install applications in MEDUSA classrooms in function of the aggressiveness level of the installation with the operating systems. 

System

Local solutions in computers are based on Microsoft Window XP. The operating system of servers is Microsoft Window Server 2000. At the present time, individualize accounts are only created for administrative and educational personnel of schools. Also, a reduced number of standard work groups can be created: one for teachers, one for administration and one for pupils. In few schools there exist collectives of teachers that request bigger levels of autonomy in the creation of services and groups. In general, these collectives coincide with teachers that have bigger capacities for ICT administration. Thereby, in Phase II the design has been improved with services that allow creating services more personalized at the schools. Solutions based on the new characteristics of Microsoft Window 2003 and Window Server 2003 with Active Directory 2.0 will be implemented. They will allow creating more flexibly different groups. Also, a better versatile creation of accounts will allow individualized accounts for pupils and a larger number of working groups.

The possibility of transparently changing the position of users and equipment is required. Two mobility profiles exist: the 'mobile' and the 'nomadic'. Although both allow mobility of users with transfer of communications of an access point to other, their mobility profile is different. The users of mobile networks we called 'mobiles': that is, they communicate while they are in movement. The users called 'nomadic', they move, stop and then communicate. The 'mobile' concept still has not been developed completely through such wireless technologies as WI-FI (IEEE 802.11 standards) (Dubendorf, 2003). These solutions have only been used to save distance. It is foreseen in Phase II to implant WI-FI areas in classrooms. The mobility characteristic that has been developed is the 'nomadic' using fixed accesses. This is linked with the experience that some teachers have acquired using notebooks and projectors. These teachers demand a bigger number of them for its use in 'classroom corners'. This demand of more equipment takes place several months after the school has been endowed with them. In Phase II a concrete action enlarging the supply of notebooks and projectors in schools is foreseen.

\section{INTEGRATED BROADBAND NETWORK}

The Integrated Broadband Network (IBN) connects all schools of the MEDUSA project. These schools are constituted mainly by head offices and schools. The IBN allows connectivity among them, with the corporate services of the Government of the Canary Islands and with the Internet. Educational personnel and office workers have access to the services of the 
Government of the Canary Islands. All the users are connected to the exterior through a unique access to the Internet. The essential servers of the architecture are located in head offices from where all information arrives for the whole educational community (figure 1). The basic aspects that have been developed in the IBN are IP network, broadband access network to schools, mobility and security.

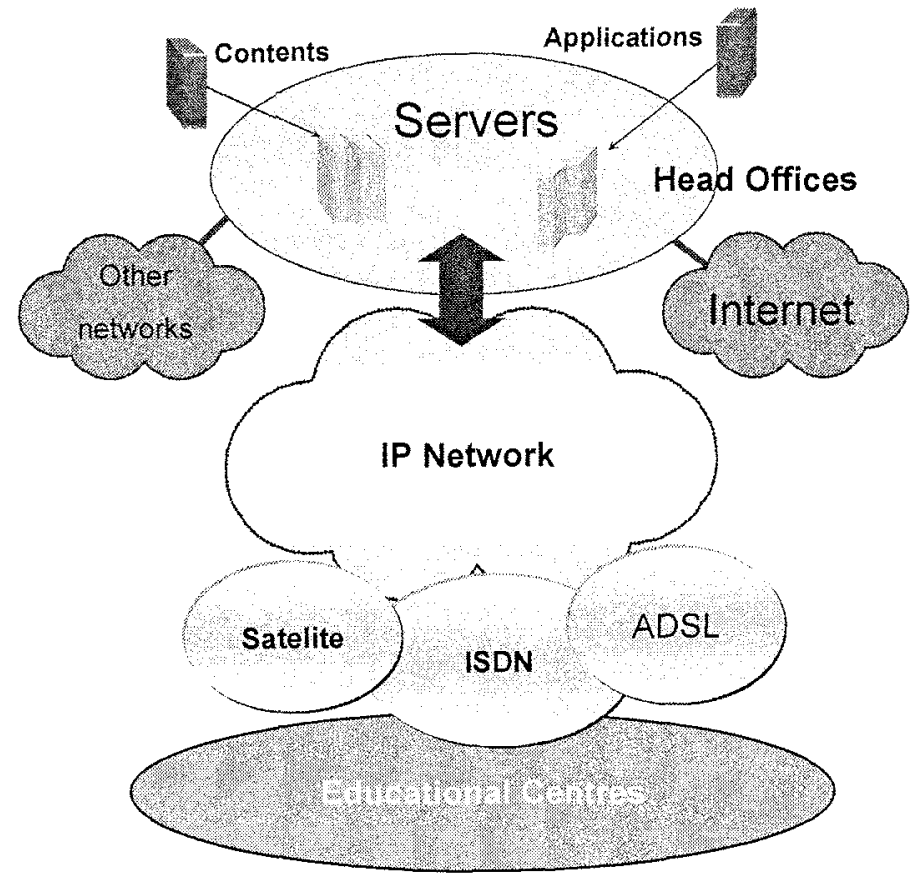

Figure 1. Integrated Broadband Network Architecture

\subsection{IP Network}

The IBN architecture is based on the use of IP protocol in the backbone and broadband technologies in accesses of schools. This solution fulfils the integrate characteristic. All the data services of the schools are integrated and come out through the same access using the IP protocol. At the present time voice services have not been included in this network. Future strategies will integrate voice using IP protocol. This way makes sure of the evolution of this network toward the IP scenario, where VoIP will be able to be incorporated in the future (Zamir, 2000). 
System

\subsection{Broadband Access Network}

Schools have been endowed with broadband accesses. Currently, of the total of schools, 1,264 , about $32 \%$ of them have access to the Internet through the IBN. $87 \%$ have ADSL accesses and the rest have ISDN accesses. At the moment, $13 \%$ of the 1,264 schools do not have either ADSL or ISDN coverage, they are in most of the cases schools located in rural areas. In the Canary Islands other available broadband technologies exist (e.g., cable modem and LMDS), although at the moment the operators that offer these technologies only have coverage in metropolitan areas. Thereby, in Phase II access by satellite has been considered as a better alternative for rural areas. The use in each access is continually monitored and it allows us to adapt the broadband necessities of each school.

ADSL access network architecture is based on points of interconnection (PoI) with the telecommunications operator. From each PoI ADSL, connections are established to each school. The capacity of each PoI is subscribed to a telecommunications operator. This solution allows having $\mathrm{ADSL}$ access that guarantees upstream and downstream speeds superiors to those that the telecommunications operators offer directly to their customers (Maxwell, 1999). Each PoI gives service to a zone of the Canary Islands, although ADSL coverage is not total in each area. In the future, superior demands of 2 Mbps could be carried out with other technologies like VDSL (Very high speed Digital Subscriber Line) access or increasing the number of ADSL access (e.g., 2xADSL) in each school. It is intended at the end of year 2006 that all the schools will have broadband accesses through the IBN.

\subsection{Mobility}

Users can be connected from any internal point to the network or from any external one (e.g., their home) conserving all functionalities as if they were in their habitual working place. Also relevant are concepts of 'mobile' and 'nomadic' user. The mobility concept that has been developed in the IBN is 'nomadic'. At present the IBN does not target the 'mobile' user. Not all users have the same necessities. Pupils, teachers and administration personal require two access points: one external to the network, in general their home, and the other internal, their school. This way, solutions can be implemented so that teachers and pupils can work or learn from their home. In these cases access can be made from outside. In some cases solutions have been developed based on VPN (Virtual Private Network) (Fowler, 1999) for pupils with special needs. 
Another group of users also require mobility among schools. In this last case mobility is guaranteed through active directory policies where each user profile is replied in all the local-area servers of each school. The replica that is carried out is incremental and scheduled nocturnally with the purpose of not saturating access. At present the active directory is implemented with Microsoft Windows Server 2000 with Active Directory 1.0. These current active directory policies permit teachers move from one school to another, so they can be connected to the other school network. First they are registered with their user names, then they will be able to carry out all the functions that they have enabled inside the IBN. These policies also permit creation of collaborative working groups among teachers of different schools. In Phase II it is intended to enlarge this function for creation of collaborative working groups to pupils. It is not intended in Phase II to develop the widest mobility concept: the data 'mobile' user. At the moment only the mobile telephony service is embraced through corporate telephony services.

\subsection{Security}

Two logical networks have been created inside the IBN: a network that it is called the educational network and another called the corporate network. The objective is to avoid pupil access to the Government of the Canary Islands corporate network. This way unwanted access by pupils to the corporate services is avoided. In Phase II the educational network will come out to the Internet through a content filter. Each school will define, inside its autonomy, the contents that are not accessible for its pupils. The corporate network gives access to the corporate services of The Government of the Canary Islands. Permission policy has been implemented through the active directory profiles that allow protection of users and equipment. Internet access is always carried out through a firewall located in central services of the Government of the Canary Islands. Security is reinforced with the ICT Centre which maintains centralized control.

\section{MANAGEMENT SYSTEM}

The Management System guarantees a unique vision of THE MEDUSA project and the fact that the implementation of ICT infrastructure fulfils its objectives. Inside the Management System, it is important to include methodologies of ICT management (Boar, 1993; Davis \& Yen, 1999). It also guarantees the availability and the quality of service (QoS) of all ICT services. One of its main missions is to reinforce the educational autonomy and friendly characteristics of the schools and security characteristics of the 
corporate environment. The Management System carries out a centralized control of the schools that are geographically very disperse. It is also important to give schools autonomy within a philosophy of high protection for the equipment, so that risks of voluntary or accidental manipulations will be diminished. Service philosophy is based on facilitating access of any user regardless of their computer literacy. The Management System is supported by the MEDUSA Office and ICT Centre.

\subsection{MEDUSA Office}

MEDUSA Office manages and has a unique vision of the entire THE MEDUSA project. It achieves different functions which emphasize the following (figure 2): executive, transformational, decentralizing and educational functions.

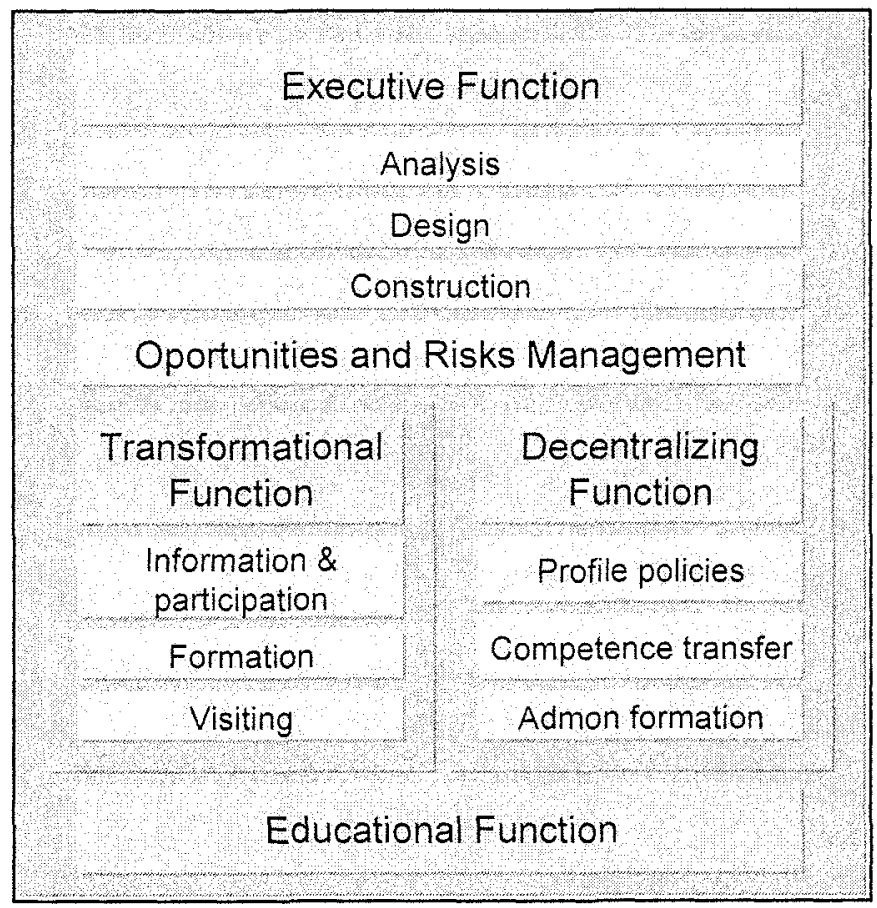

Figure 2. MEDUSA Office Functions

The mission of the executive function is to have a unique vision and to fulfill the objectives of the MEDUSA project. It manages and plans the MEDUSA project. In a project of these characteristics success will not only depend on good management of all technical tasks, but also to its capacity of adjusting to new situations. When dealing with a project of long duration, management of risks and opportunities is also carried out. 
The mission of the transformational function is to manage the change and to eliminate the resistances of all type of people in the educational system. It fulfils the transformation characteristics. Change management has identified three types of functions: leadership, commitment and knowledge (Huber \& Glick, 1993). These functions have been developed in the MEDUSA project through a complete management method that integrates the deployment of the infrastructures in schools with schemes of presentations, visits and courses. The experience in the MEDUSA project has evidenced that change management is indissolubly together with installation of ICT infrastructure. When the deployment of the technological architecture goes with actions of change management a larger increment of the demand of ICT formative and more personalized ICT solutions or services have taken place. This has led to redefine the formative planning and to develop in Phase II a service with a more individualized support from MEDUSA office.

The mission of the decentralizing function is to facilitate autonomy of the school in execution of its educational project. It reinforces the educational autonomy. Schools that want more autonomy in administration of their ICT resources and whose teachers have advanced knowledge can have delegated a great part of the work of computer system administration. As a result, when a school acquires bigger abilities in the administration of computer systems, a procedure has been enabled so that the school can receive bigger technical powers. The educational function propitiates the popularization, extension and support to a wide group of educational applications. This function favours the use of corporate applications with independence that each school can select other different ones.

\subsection{ICT Centre}

ICT Centre manages and administers the whole ICT infrastructure, as well as a level of attention and service to all users. ICT Centre is the most technical level in the Management System. All servers and computers of the schools can be managed and administrated from ICT Centre. Computer environments of the schools are monitored so that actions to prevent the systems becoming unstable or saturated can be carried out.

From this centre all users are assisted. ICT Centre has been endowed with an organizational structure and technological tools to carry out the centralized administration of ICT resources. ICT Centre gives support to the systems and users of the Individualized Schools Networks and those of the IBN. It has a group of tools and functions to provide a wide range of services (figure 3). ICT Centre provides support to the users of all the schools and administrative centres. All kind of inquires, problems, petitions or mishaps 
are managed until their complete resolution. It is constituted as a unique point of direct attention available 24 hours a day, 7 days a week and 365 days a year. In an environment, where schools are dispersed, monitoring of all their components is absolutely necessary as well as remote assistance, with the purpose of avoiding long time waiting for answers. Remote control is made through the distribution of agents to all computers and servers.

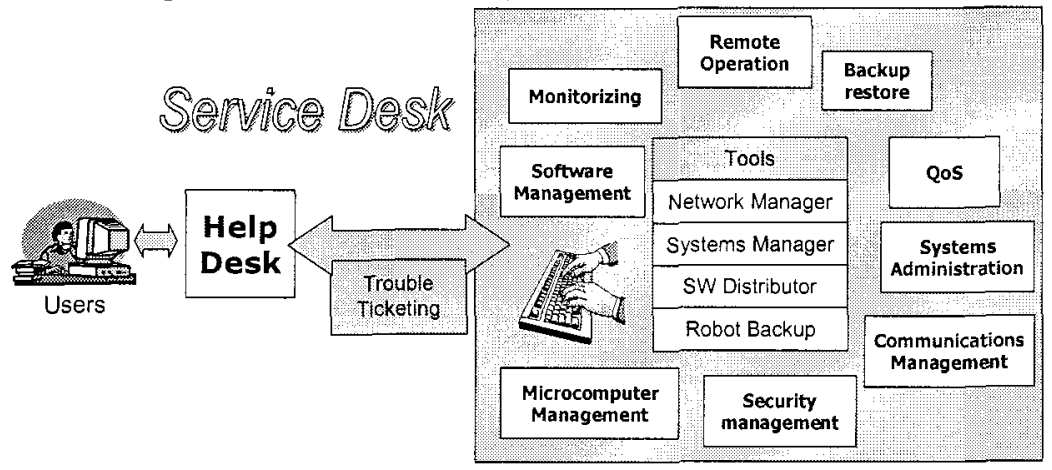

Figure 3. Tools and functions of ICT Centre

ICT Centre also gives quick answers to new necessities or upgrades of educational applications, office applications and operating systems. Software distribution services allow the centralized definition of software packages and centralized planning and pursuing of its distribution. Personalized distribution is necessary for groups of computers, servers, users or locations. ICT Centre performs quality control prior to software distribution in schools.

An improvement in levels of QoS has occurred during Phase I. This has led to upgrade ICT Centre. The demand of more QoS has been increasing for two reasons: first, the educational community makes bigger use of the central services and, second, the demand for quicker answers to user inquires has increased. In Phase II ICT Centre is going to be improved with special attention to the improvement of the software distribution service.

\section{CONCLUSION}

The basic technological architecture has been designed starting from definition of the characteristics that should complete ICT integration with the educational system. This architecture has been materialized in three clearly differentiated evolutionary projects: The Individualized Networks of the Schools, Integrated Broadband Network and Management System. With these three evolutionary projects all the characteristics would be fulfilling the basic ICT necessities of schools and the corporate environment. 
At the present time, the current solution completes a great part of the characteristics of the environment of the school and corporate environment. Nevertheless, the demand of the educational community makes still necessary to keep on improving the service. Thus, in Phase II of THE MEDUSA project the mobility concept inside the school will be improved through the incorporation of wireless technologies. Currently, it is not being considered high-priority to enlarge the mobility concept to the 'mobile' users or to improve the integration concept with the incorporation of VoIP.

Finally, it is necessary to increase levels of school autonomy. This will be carried out in Phase II through two actions: competences transferring of Management System to schools and developing other functionalities that allow accounts creation for pupils and a bigger flexibility in creation of work groups. In Phase II levels of QoS will be increased to improve characteristics of friendliness and intelligence through upgrading ICT Centre.

\section{REFERENCES}

Boar, B.H. (1993). The Art of Strategic Planning for Information Technology. John Wiley.

Cabrera, J. M. \& Afonso, J. M (2002). El sistema educativo en Canarias. Una perspectiva socioeconómica. Consejo Económico y Social. http:/www.cescanarias.org/

CECD, (2003). Consejería de Educación, Cultura y Deportes del Gobierno de Canarias. http://www.educa.rcanaria.es/

CIDE (Centro de Investigación y Documentación Educativa). (2002). Spanish Education System. Ministerio de Educación, Cultura y Deporte: Dirección General de Educación, Formación Profesional e Innovación Educa. www.mec.es/cide/publicaciones/pub cide.htm

Davis, W. \& Yen, D. (1999). The Information System Consultant's Handbook: Systems, Analysis and Design. CRC Press LLC.

Dubendorf, V. A. (2003). Wireless Data Technologies. John Wiley \& Sons Ltd.

Fowler, D. (1999). Virtual private networks. Morgan Kaufmann Publishers.

GC (Gobierno de Canarias). (2003). Plan para el desarrollo de la Sociedad de la Información de Canarias (PDSIC). http://www.gobiernodecanarias.org/dgtsi/pdsic.pdf

Goncalves, M. \& Niles, K. (1998). IPv6 Networks. McGraw-Hill.

Harney, J. (2002). Application Service Providers (ASPs): A Manager's Guide. Ad. Wesley.

Huber, G.P. \& Glick W.H., (1993). Organizational Change and Redesign. Ideas and Insights for Improving Performance. Oxford University Press.

ISTAC, (2003). Instituto Canario de Estadística. http:/www.gobiernodecanarias.org/istac/

Maxwell, K. (1999). Residencial Broadband. Wiley.

Pelgrum, W. J. (2001). Obstacles to the integration of ICT in education: results from a worldwide educational assessment. Computer \& Education, 37 (2), 163-178.

Saunders, S. (1996). The McGraw-Hill High-Speed LANs Handbook. McGraw-Hill.

Wisely, D., Eardley, P. \& Burness, L. (2002). IP for 3G-Networking Technologies for Mobile Communications. John Wiley \& Sons.

Zamir, S. (Ed.) (2000). Handbook of Emerging Communications Technologies: The Next Decade. CRC Press LLC. 